\title{
Myofascial Release Menurunkan Nyeri dan Meningkatkan Fungsional Leher Myofascial Pain Syndrome Otot Upper Trapezius
}

\author{
Adinda Riestiani Hernatha Putri ${ }^{1}$, Sulistyaningsih ${ }^{2 *}$ \\ ${ }^{1,2}$ Fakultas Ilmu Kesehatan, Universitas 'Aisyiyah Yogyakarta \\ *Email: sulistyaningsih@unisayogya.ac.id
}

\begin{abstract}
Background: Complaints due to upper trapezius myofascial pain syndrome include spasm, pain, and limitations in functional motion of the neck and surrounding areas. One way to overcome this is myofascial release, but there is no review article about the effect of myofascial release on the functional neck of myofascial pain syndrome. This study is to analyze the effect of myofascial release on pain and functional neck myofascial pain syndrome in the upper trapezius muscle. Methods: systematic review with the PICO framework (Population, Intervention, Comparison, Outcomes). Identify articles using relevant databases (Googlescholar, PubMed, PeDro) with customized keywords. Article selection using PRISMA flowchart, article assessment using critical appraisal. Results: The number of articles from 3 databases contained 3684 articles. After screening the title and the relevance of the abstract, 10 articles were obtained that proved the effectiveness of myofascial release in reducing neck pain and disability. Conclusion: myofascial release technique in the condition of myofascial pain syndrome, upper trapezius muscle is effective for reducing pain and increasing functional motion in the neck.
\end{abstract}

Keywords: neck disability, myofascial release, myofascial pain syndrome, trigger points upper trapezius

\section{PENDAHULUAN}

Myofascial pain syndrome (MPS) merupakan keadaan munculnya rasa sakit pada bagian otot upper trapezius yang diawali dengan munculnya titik nyeri (trigger point) (Sunyiwara et al., 2019). Trigger point adalah kondisi dimana terdapat titik nyeri pada otot yang mengalami myofascial pain syndrome sehingga menimbulkan spasme pada otot yang terkena (Atmadja, 2016). MPS upper trapezius sering terjadi pada populasi umum, prevalensi MPS di Indonesia dalam 1 tahun mencapai 40\% (Sunyiwara et al., 2019). MPS sering terjadi pada perempuan daripada laki-laki (Kaprail et al., 2019).

Nyeri yang muncul dalam waktu yang lama dapat mengakibatkan keterbatasan pada anggota gerak fungsional. Otot upper trapezius merupakan otot rangka yang berfungsi sebagai control pada gerakan cervical, sehingga apabila otot tersebut mengalami ketegangan atau kaku akibat MPS dapat mempengaruhi gerak fungsional leher menjadi terganggu (Fatmawati, 2013).

Myofascial release merupakan teknik pijatan manual yang bertujuan untuk meregangkan fascia, mengurangi perlengketan jaringan dan meperbaiki struktur jaringan lunak sehingga dapat mengurangi nyeri dan mengembalikan gerak fungsional secara normal (Maruli et al., 2014). Gerakan friction pada myofascial release yang diberikan sesuai dengan arah serat otot efektif dalam menghilangkan trigger point, memungkinkan serat otot untuk bergerak lebih normal, meningkatkan aliran darah melalui jaringan dan penurunan sensitivitas saraf dan otot (Kaprail et al., 2019).

Mengingat banyaknya kasus MPS yang dapat menyebabkan penurunan gerak fungsional leher pada tingkat usia remaja hingga lansia (Sunyiwara et al., 2019) serta belum ditemukan review terkait hal 
tersebut, sehingga perlu dilakukan studi analisis.Tujuan penelitian ini untuk mengetahui pengaruh myofascial release terhadap nyeri dan fungsional leher.

\section{METODE PENELITIAN}

Metode penelitian menggunakan metode systematic review. Systematic review merupakan metode dalam melaksanakan review artikel dengan standar, kriteria, terstruktur dan direncanakan sebelum pelaksanaan sistesis artikel (Hariyati, 2010). Pencarian jurnal menggunakan 3 database diantaranya, Google scholar, PubMed dan PeDro.Kerangka kerja yang digunakan sebagai strategi untuk pencarian kata kunci artikel yaitu dengan framework PICO (Riva et al., 2012). Kerangka kerja ini memiliki 4 komponen yang terdiri dari P: population (myofascial pain syndrome upper trapezius), I: intervention (myofascial release), C: comparison (EPA atau exercise lain), $\mathrm{O}$ : outcome (peningkatan gerak fungsional leher).
Artikel yang telah diperoleh sesuai dengan kriteria eligibilitas (Murti, 2010). Artikel yang termasuk dalam kriteria inklusi diantaranya original article, artikel yang di terdapat full text, artikel yang diterbitkan dalam bahasa Inggris, artikel yang diterbitkan dalam waktu 10 tahun terakhir (2010), artikel yang berhubungan dengan manusia, desain penelitian eksperimen, dan artikel yang membahas tentang pengaruh myofascial release tehadap nyeri dan fungsional leher otot upper trapezius. Kriteria eksklusi diantaranya artikel yang menggunakan judul bahasa inggris tetapi penjelasan menggunakan bahasa selain bahasa Inggris, artikel dalam bentuk naskah publikasi, artikel opini, dan artikel berbayar.

Tahap selanjutnya dilakukan penyaringan data termasuk data duplikasi, screening abstrak, screening full text yang beorientasi pada kriteria inklusi dan eksklusi yang telah ditetapkan dengan menggunakan PRISMA flowchart (Moher et al., 2015).

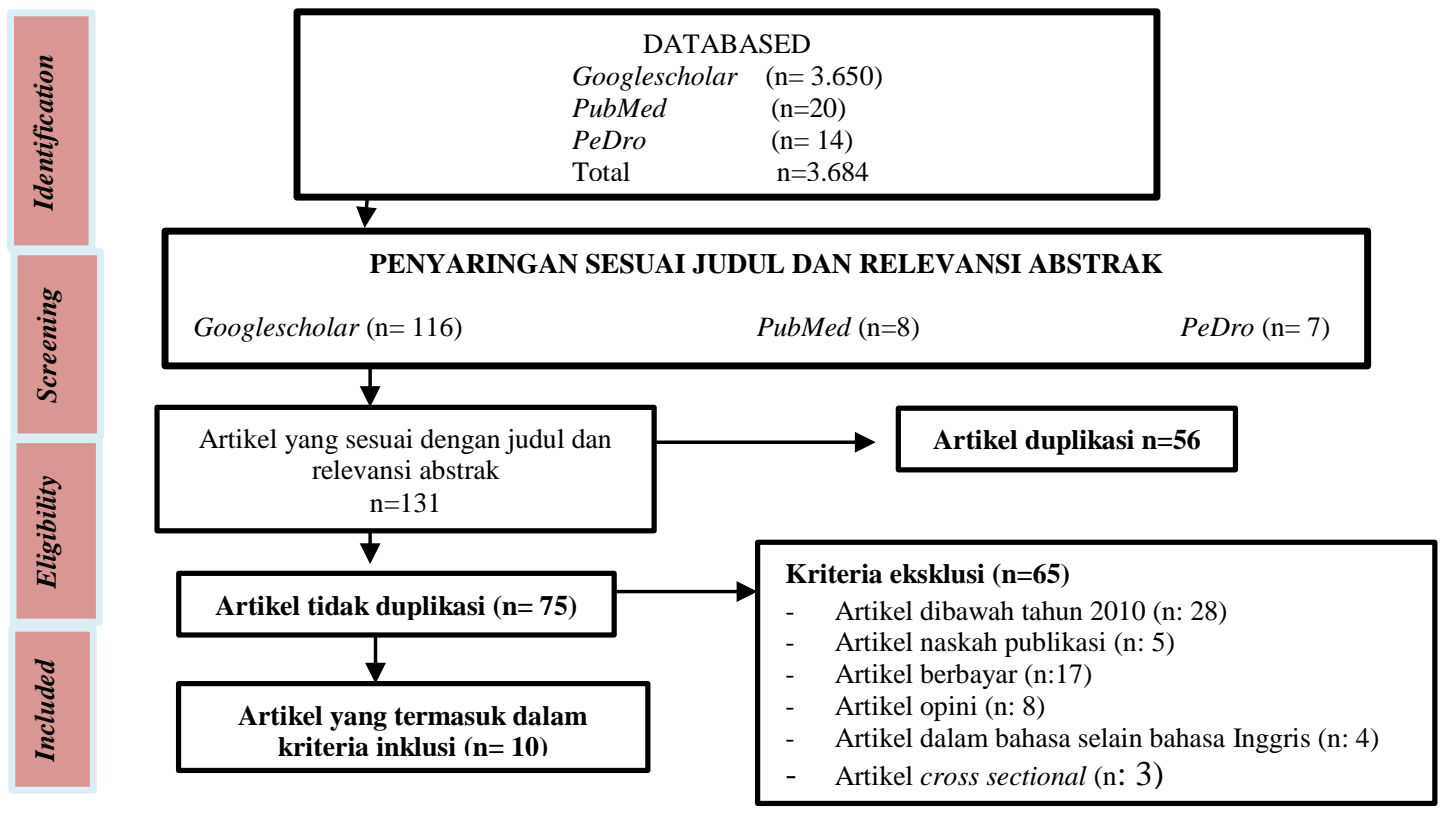

Gambar 1. Bagan PRISMA Flowchart 


\section{HASIL PENELITIAN}

Hasil studi literatur dari 3 database diperoleh sebanyak 3.684 artikel kemudian dilakukan screening judul artikel dan diperoleh 131 artikel. Seleksi artikel yang sesuai dengan kriteria eligibility sehingga didapatkan hasil akhir 10 artikel selanjutnya dilakukan penilaian artikel dengan menggunakan JBI (Joanna Bringss Institute) critical appraisal dan selanjutkan dilakukan review. Sebanyak 10 artikel yang terpilih terdiri dari berbagai karakteristik diantaranya karakteristik negara dan desain penelitian. Karakteristik negara pada artikel terdiri dari negara maju yaitu 3 artikel diperoleh dari benua Eropa (Spanyol), dan yang berasal dari negara berkembang terdapat 6 artikel di benua Asia (India), serta 1 artikel berasal dari benua Afrika (Mesir). Karakteristik desain penelitian diperoleh 5 artikel denga desain quasi eksperimental dan 5 artikel dengan desain Randomized Controlled Trial (RCT).
Hasil keseluruhan artikel menyatakan bahwa myofascial release berpengaruh dalam mengurangi nyeri dan meningkatkan fungsional leher pada penderita myofascial pain syndrome upper trapezius. Dari 10 artikel penggunaan dosis myofascial release dikelompoknya menjadi 3 yaitu 30-60 detik 5 kali pengulangan, $90-120$ detik 3 kali pengulangan, dan 2-3 menit 3 kali pengulangan.Instrumen alat ukur yang digunakan untuk mengetahui tingkat gangguan fungisonal leher yaitu menggunakan NDI (Neck Disability Index) dan NPQ (Northwick Park Questionnaire). Karakteristik penderita myofascial pain syndrome upper trapezius diantaranya lebih sering terjadi pada jenis kelamin wanita, kategori usia 20-50 tahun dengan jenis pekerjaan yang dilakukan dalam posisi statis dan waktu yang lama seperti operator dan pekerja kantor dengan penggunaan computer

Tabel 1. Hasil Ulasan Artikel Penelitian

\begin{tabular}{|c|c|c|c|c|c|c|}
\hline Hasil Review & p Value & $\begin{array}{c}\text { Nilai } \\
\text { RR }\end{array}$ & Nilai CI & $\begin{array}{c}\text { Desain } \\
\text { Penelitian }\end{array}$ & Peneliti & $\begin{array}{l}\text { Koding } \\
\text { Artikel }\end{array}$ \\
\hline $\begin{array}{l}\text { Pengaruh } \\
\text { myofascial release } \\
\text { terhadap nyeri } \\
\text { dan fungsional } \\
\text { leher myofascial } \\
\text { pain syndrome }\end{array}$ & & & & & & \\
\hline $\begin{array}{l}\text { upper trapezius } \\
\text { a. Direct } \\
\text { Myofascial } \\
\text { Release }\end{array}$ & $\begin{array}{l}(p=0,003) \\
(p=0,000) \\
(p=0,05)\end{array}$ & $(0,10)$ & $\begin{array}{l}(1,99-11,23) \\
(8,96-12,15) \\
(0,83-1,42)\end{array}$ & $\begin{array}{l}\text { RCT } \\
\text { RCT } \\
\text { RCT }\end{array}$ & $\begin{array}{l}\text { (Rodríguez- } \\
\text { Huguet, } \\
\text { Rodríguez- } \\
\text { Almagro, } \\
\text { Rodríguez- } \\
\text { Huguet, Martín- } \\
\text { Valero, \& Lomas- } \\
\text { Vega, 2020), }\end{array}$ & $\begin{array}{l}\text { A1 } \\
\text { A3 } \\
\text { A4 }\end{array}$ \\
\hline $\begin{array}{l}\text { b. Indirect } \\
\text { Myofascial } \\
\text { Release }\end{array}$ & $\begin{array}{l}(\mathrm{p}=0,00) \\
(\mathrm{p}=0,0009)\end{array}$ & & & $\begin{array}{l}\text { eksperimen } \\
\text { tal group } \\
\text { design } \\
\text { eksperimen } \\
\text { tal group }\end{array}$ & $\begin{array}{l}\text { (Rodríguez- } \\
\text { Fuentes et al., } \\
\text { 2016), dan } \\
\text { (Rodríguez- }\end{array}$ & A10 \\
\hline
\end{tabular}




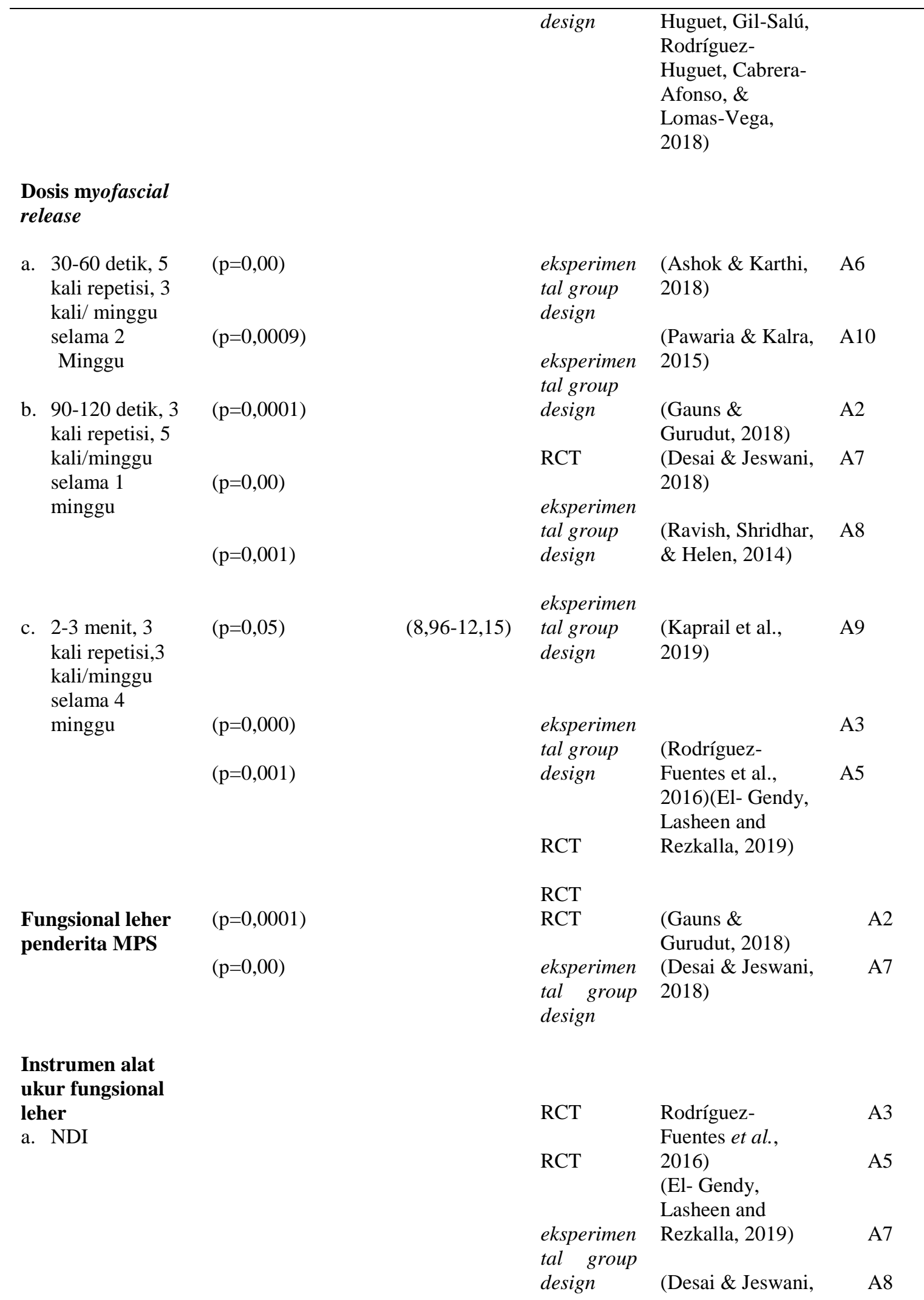


b. NPQ

b. Usia 20-50 tahun

c. Pekerjaan (operator, pekerja kantor dengan komputer)

\section{Karakteristik \\ upper trapezius}

Jenis kelamin

(wanita lebih

daripada pria)

$\begin{array}{ll}\text { eksperimen } & 2018) \\ \text { tal group } & \text { (Ravish et al., } \\ \text { design } & 2014 \text { ) }\end{array}$

RCT

(Gauns \&

Gurudut, 2018)

$\begin{array}{lll}\text { RCT } & \begin{array}{l}\text { (Rodríguez- } \\ \text { Fuentes } \text { et al., } \\ \text { 2016) } \\ \text { RCT }\end{array} & \text { A3 } \\ \begin{array}{l}\text { (Rodríguez- } \\ \text { tal group } \\ \text { design }\end{array} & \begin{array}{l}\text { 2018) } \\ \text { (Kaprail et al., } \\ \text { 2019) }\end{array} & \text { A9 } \\ \begin{array}{l}\text { RCT } \\ \text { eksperimen } \\ \text { tal group } \\ \text { design }\end{array} & \begin{array}{l}\text { (Gauns \& } \\ \text { (Ravish et al., }\end{array} & \text { A2 } \\ \text { 2014) } \\ \begin{array}{l}\text { eksperimen } \\ \text { tal group } \\ \text { design }\end{array} & \begin{array}{l}\text { (Ashok \& Karthi, } \\ \text { 2018) } \\ \text { eksperimen } \\ \text { tal group } \\ \text { design }\end{array} & \text { A7 } \\ & \text { (Desai \& Jeswani, }\end{array}$
2018)

\section{PEMBAHASAN}

Hasil dari 10 artikel yang telah di review seluruhnya membuktikan bahwa myofascial release efektif dalam menangatasi nyeri dan gangguan fungsional leher. Teknik myofascial release merupakan teknik yang dilakukan dengan menggunakan tangan untuk memobilisasi jaringan lunak yang bertujuan untuk melepaskan perlengketan pada fascia, menyebabkan fascia terelongasi sehingga muncul efek rileksasi yang dapat mengurangi nyeri dan meningkatkan lingkup gerak sendi serta memperbaiki struktur pada jaringan lunak (Maruli et al., 2014). Pengaruh pemberian myofascial release dalam meningkatkan fungsional leher myofascial pain syndrome terjadi karena adanya efek relaksasi yang terjadi pada otot yang mengalami ketegangan sehingga otot dapat kembali elastis dan bekerja sesuai fungsinya (Kaprail et al., 2019).

Myofascial release menyebabkan hiperemia aktif atau bertambahnya aliran darah di area trigger points kemudian muncul mekanisme reflek spinal yang menyebabkan penurunan spasme otot (Ashok \& Karthi, 2018). Hal ini sesuai penelitian yang dilakukan oleh Warenski (2011) penerapan myofascial release technique dapat mengurangi nyeri 
muskuloskeletal dengan menggunakan gate control theory, interpersonal attention dan parasympathetic respon pada syaraf otonom, dan pelepasan serotonin. Penjelasan lebih lanjut lagi secara fisiologis adanya pelepasan biokimia dari tubuh seperti histamin dan serotonin akan menyebabkan vasodilatasi dan permeabilitas pembuluh darah yang secara mekanis melakukan penataan kembali pada struktur jaringan pada otot. Pelaksanaan teknik myofascial release yang berfokus pada tekanan, dapat memanjangkan myofascial bertujuan melepas perlengketan jaringan dan penurunan rasa sakit melalui gate control theory, memperbaiki kualitas cairan jaringan fascia, fleksibilitas jaringan dan fungsi sendi (Stillerman et al., 2016).

Terdapat 2 tipe myofascial release yang diterapkan dalam penelitian yaitu direct myofascial release dan indirect myofascial release (Desai \& Jeswani, 2018). Pelaksanaan DMR dilakukan dengan pemberian stretch durasi panjang pada fascia yang terdapat titik nyeri kemudian tekanan diberikan secara langsung pada area yang trigger points dan dilakukan dengan kontak langsung pada kulit hingga mencapai jaringan bagian dalam untuk melepaskan perlengketan jaringan pada fascia (Desai \& Jeswani, 2018). Pelaksanaan release pada indirect myofascial release (IMR) peregangan dilakukan dengan tahanan hingga fascia rileks dengan sendirinya. Traksi dilakukan pada pada fascia untuk meningkatkan aliran darah di area tersebut sehingga dapat mengurangi nyeri atau rasa sakit dan mengembalikan kinerja optimal pada tubuh (Lucett, 2011).

Dosis pelaksanaan myofascial release yang di gunakan dalam 10 artikel penelitian yang telah di review menggunakan dosis berbeda-beda diantaranya terdapat 2 artikel penelitian yaitu A6 dan A10 menyebutkan bahwa pelaksanaan release pada area otot yang mengalami ketegangan selama 30-60 detik 5 kali repetisi dilakukan 3 kali seminggu selama 2 minggu dapat memberikan efek relaksasi sehinggga dapat menurunkan tonus otot yang mengalami pengerasan, sedangkan 4 artikel lainnya yaitu A2, A7, A8 dan A9 dalam penelitiannya menggunakan dosis pelaksanaan myofascial release selama 90-120 detik diulang 3 kali repetisi dilakukan 5 kali per minggu selama 1 minggu terbukti efektif dalam menurunkan nyeri dan meningkatkan gerak fungsional leher.

Kondisi ini sejalan dengan penelitian yang telah dilakukan sebelumnya oleh Monteiro et al (2017), bahwa didapatkan hasil yang lebih baik dengan pemberian roller massage selama 120 detik dan dapat dilakukan satu kali sehari sebelum beraktivitas sebagai pemanasan atau setelah pemulihan. Tekanan yang diberikan selama 30-90 detik dapat menimbulkan efek penurunan nyeri jangka pendek dan penerapan tekanan vertical menyebabkan pemanjangan sarkomer yang memendek sehingga dapat kembali memanjang seperti posisi semula. Posisi ini dapat mencegah munculnya reflek stretch dan mungkin dapat mengalami penurunan sensitivitas otot (Ashok \& Karthi, 2018).

Gangguan fungsional leher biasanya disebabkan oleh adanya penekanan yang berlebihan dan ketegangan pada otot upper trapezius, otot upper trapezius merupakan salah satu otot postural yang rentan digunakan secara berlebihan (Desai \& Jeswani, 2018). MPS otot upper trapezius sering terjadi akibat postur yang buruk sehingga menimbulkan gangguan 
pada gerak fungsional leher (Gerber et al., 2011). Bekerja dalam postur tubuh yang canggung serta penggunaan fasilitas kerja yang tidak sesuai menyebabkan otot menjadi tertekan, tekanan yang berlebihan akan menyebabkan ketegangan pada otot upper trapezius sehingga dapat menurunkan rentan gerak sendi leher, kemudian rentan gerak yang terbatas mengakibatkan peningkatan kekakuan pada jaringan lunak (Bron \& Dommerholt, 2012). Instrumen penelitian yang digunakan untuk mengukur tingkat fungsional leher pada keseluruhan 10 artikel 9 diantaranya menggunakan neck disability index questionnaire (NDI) sedangkan 1 artikel menggunakan Northwick park neck pain questionnaire (NPQ).

MPS banyak terjadi pada perempuan di India perbandingan jenis kelamin antara laki-laki dan perempuan yaitu 1:10 (Ashok \& Karthi, 2018). Usia produktif antara 20-50 tahun memiliki resiko tinggi terkena MPS. Semakin tinggi aktivitas yang dilakukan tanpa diimbangi dengan olahraga dan gaya hidup sehat dapat meningkatkan faktor terjadinya MPS akibat kelelahan otot yang berkepanjangan. Jenis pekerjaan yang sering memicu timbulnya MPS yaitu pekerjaan yang dilakukan dalam kondisi statis dan pekerjaan yang menggunakan komputer dalam jangka waktu yang cukup lama dapat menyebabkan postur tubuh yang buruk,akibat postur yang buruk (Desai \& Jeswani, 2018). Otot di dalam tubuh menjadi mudah stres sehingga mudah mengalami spasme otot. Dalam jangka waktu yang lama dapat menimbulkan adanya taut band trigger point yang merupakan titik nyeri MPS dan dapat menganggu gerak fungsional anggota gerak tubuh menjadi terbatas (Ashok \& Karthi, 2018).

\section{KESIMPULAN DAN SARAN}

Hasil 10 artikel seluruhnya membuktikan bahwa myofascial release terbukti efektif dalam menurunkan nyeri dan meningkatkan gerak fungsional leher. Teknik myofascial release merupakan salah satu intervensi fisioterapis yang dapat digunakan dalam penanganan kondisi myofascial pain syndrome dengan arah release mengikuti arah serat otot upper trapezius. Dosis pelaksanaan myofascial release dapat dilakukan selama 90-120 detik diulang 5 kali seminggu selama 1 minggu untuk melepaskan trigger points dan mengurangi spasme otot sehingga dapat menurunkan tingkat nyeri dan mengembalikan fungsi normal otot. NDI dan NPQ merupakan instrumen alat ukur berupa kuesioner yang digunakan untuk mengetahui tingkat gangguan fungsional leher.

Karakteristik penderita myofascial pain syndrome sering terjadi pada jenis kelamin perempuan, usia (20-50 tahun) dengan jenis aktifitas atau pekerjaan yang dilakukan dalam kondisi statis dan penggunaan komputer dalam waktu lama. Fisioterapis disarankan dapat mengaplikasikan teknik myofascial release sebagai salah satu intervensi fisioterapi untuk mengurangi spasme dan mengembalikan gerak fungsional leher pada kondisi pasien yang mengalami MPS pada otot upper trapezius. Pelaksanaan myofascial release dapat dilakukan dengan teknik direct myofascial release dengan arah release searah dengan serabut otot upper trapezius.Peneliti selanjutnya disarankan melakukan meta analisis terkait dosis yang paling efektif menurunkan nyeri dan meningkatkan 
fungsional leher MPS otot upper trapezius.

\section{DAFTAR RUJUKAN}

Ashok, N., \& Karthi, M. C. (2018). Immediate Effect of Myofascial Trigger Point Release on Chronic Neck Pain among Visual Display Terminal Operators. International Journal of Research and Scientific Innovation (IJRSI), V(I), 95-97.

Atmadja, A. S. (2016). Sindrom Nyeri Myofascial. $C d k, 43(3)$, 176-179. Retrieved from http://www.cdkjournal.com/index.p $\mathrm{hp} / \mathrm{CDK} /$ article/download/29/26

Bron, C., \& Dommerholt, J. D. (2012). Etiology of myofascial trigger points. Current Pain and Headache Reports, 16(5), 439-444. https://doi.org/10.1007/s11916-0120289-4

Desai, S., \& Jeswani, K. (2018). To compare the effect of myofascial release and ischaemic compression on pain, cervical lateral flexion and function in acute Trapezitis in young adults. International Journal of Applied Research, 4(3), 448-454.

El-Gendy, M. H., Lasheen, Y. R., \& Rezkalla, W. K. S. (2019). Multimodal approach of electrotherapy versus myofascial release in patients with chronic mechanical neck pain: A randomized controlled trial. Physiotherapy Quarterly, 27(4), 612.https://doi.org/10.5114/pq.2019.8 7735
Fatmawati, V. (2013). the Decreasing Pain and Disability With Integrated Neuromuscular Inhibition Techniques (Init ) and Massage Effleuragge in Myofacial Trigger Point of Upper Trapezius Muscle. Sport and Fitness Journal, 1(1), 6071.

Gauns, S. V, \& Gurudut, P. V. (2018). A randomized controlled trial to study the effect of gross myofascial release on mechanical neck pain referred to upper limb. International Journal of Health Sciences, 12(5), 51-59. Retrieved from http://www.ncbi.nlm.nih.gov/pubme d/30202408\%0Ahttp://www.pubme dcentral.nih.gov/articlerender.fcgi?a rtid=PMC6124822

Gerber, N., Sikdar, S., Hammond, J., \& Shah, J. (2011). A brief overview and update of myofascial pain syndrome and myofascial trigger points. Journal of The Spinal ..., 6(1), 55-64. Retrieved from https://www.spinerf.org/sites/default /files/journal/A Brief Overview and Update of Myofascial Pain Syndrome and Myofascial Trigger Points.pdf

Hariyati, R. T. S. (2010). Mengenal Systematic Review Theory dan Studi Kasus. Jurnal Keperawatan Indonesia, 13(2), 124-132. https://doi.org/10.7454/jki.v13i2.24 2

Kaprail, M., Jetly, S., Sarin, A., \& Kaur, P. (2019). To Study the Effect of Myofascial Trigger Point Release in Upper Trapezius Muscle Causing 
Neck Disability in Patients with Chronic Periarthritis Shoulder. Sport Exerc Med Open J, 5(1), 1-4. https://doi.org/10.17140/semoj-5167

Maruli, W. O., Sutjana, I. D., \& Indrayani, A. W. (2014). Perbandingan Myofascial Release Technique dengan Contract Relax Stretching terhadap penurunan nyeri pada sindroma Myofascial otot Upper Trapezius. Majalah Ilmiah Fisioterapi Indonesia, 2(3), 3. Retrieved from https://ojs.unud.ac.id/index.php/mifi /article/view/8470/6314

Moher, David, Larissa Shamseer, Mike Clarke, Davina Ghersi, Alessandro Liberati, Mark Petticrew, Paul Shekelle, and Lesley A Stewart. 2015. "Preferred Reporting Items for Systematic Review and MetaAnalysis Protocols (PRISMA-P) 2015 Statement." Systematic Reviews. https://doi.org/10.1186/2046-40534-1.

Monteiro, E. R., Vigotsky, A., Škarabot, J., Brown, A. F., Ferreira de Melo Fiuza, A. G., Gomes, T. M., ... da Silva Novaes, J. (2017). Acute effects of different foam rolling volumes in the interset rest period on maximum repetition performance. Hong Kong Physiotherapy Journal, 36, 57-62. https://doi.org/10.1016/j.hkpj.2017.0 3.001

Murti, B. (2010). Desain Dan Ukuran Sampel Untuk Penelitian Kuantitatif
Dan Kualitatif Di Bidang Kesehatan (Ed Revisi). Yogyakarta: Universitas Gadjah Mada Press.

Pawaria, S., \& Kalra, S. (2015). Comparing Effectiveness of Myofascial Release and Muscle Stretching on Pain, Disability and Cervical Range of Motion in Patients with Trapezius Myofascial Trigger Points. Indian Journal of Health Sciences and Care, 2(1), 8. https://doi.org/10.5958/23942800.2015.00002.4

Ravish, Shridhar, \& Helen, S. (2014). To Compare the Effectiveness of Myofascial Release Technique Versus Positional Release Technique With Laser in Patients With Unilateral Trapezitis. Journal of Evolution of Medical and Dental Sciences, 3(9), 2161-2166. https://doi.org/10.14260/jemds/2014 $/ 2121$

Riva, J. J., Malik, K. M. P., Burnie, S. J., Endicott, A. R., \& Busse, J. W. (2012). What is your research question? An introduction to the PICOT format for clinicians. The Journal of the Canadian Chiropractic Association, 56(3), 167-171. Retrieved from http://www.ncbi.nlm.nih.gov/pubme d/22997465\%0Ahttp://www.pubme dcentral.nih.gov/articlerender.fcgi?a rtid=PMC3430448

Rodríguez-Fuentes, I., De Toro, F. J., Rodríguez-Fuentes, G., De Oliveira, I. M. H., Meijide-Faílde, R., \& Fuentes-Boquete, I. M. (2016). Myofascial release therapy in the 
treatment of occupational mechanical neck pain: A randomized parallel group study. American Journal of Physical Medicine and Rehabilitation, 95(7), 507-515.

https://doi.org/10.1097/PHM.00000 00000000425

Rodríguez-Huguet, M., Gil-Salú, J. L., Rodríguez-Huguet, P., CabreraAfonso, J. R., \& Lomas-Vega, R. (2018). Effects of Myofascial Release on Pressure Pain Thresholds in Patients with Neck Pain: A Single-Blind Randomized Controlled Trial. American Journal of Physical Medicine and Rehabilitation, 97(1), 16-22. https://doi.org/10.1097/PHM.00000 00000000790

Rodríguez-Huguet, M., RodríguezAlmagro, D., Rodríguez-Huguet, P., Martín-Valero, R., \& Lomas-Vega, R. (2020). Treatment of Neck Pain With Myofascial Therapies: A Single Blind Randomized Controlled Trial. Journal of Manipulative and Physiological Therapeutics, 00(00), 11-13. https://doi.org/10.1016/j.jmpt.2019. 12.001

Stillerman, E., Riggs, A., \& Grant, K. E. (2016). Myofascial Release. In Modalities for Massage and Bodywork chapter 9 (pp. 149-166).

Sunyiwara, A. S., Putri, M. W., \& Sabita, R. (2019). Pengaruh Myofacial Release Kombinasi dengan Hold Relax terhadap Myofacial Pain Syndrome. Jurnal Ilmiah Kesehatan
(JIK), 12(2), 582-587.

Warenski, J. (2011). The Effectiveness of Myofascial Release Technique In The Treatment Of Myofascial Pain : A Literature Review. Journal of Musculoskeletal Pain, 23, 27-35. 